\title{
Pigmented fungiform papillae of the tongue: Moroccan case
}

\section{Ouiam El Anzi, Safae Maouni, Ilham Meknassi, Badredine Hassam}

Department of Dermatology-Venereology, Ibn Sina University Hospital, Mohammed V University, Rabat, Morocco

Corresponding author: Dr. Ouiam El Anzi, E-mail: elanzi.ouiam@gmail.com

Sir,

Fungiform papillae are red or pink, mushroom-shaped projections located on the tip, dorsal or lateral parts of the tongue, containing several taste buds. When they are brown to black in colour, they are referred as pigmented fungiform papillae of the tongue (PFPT). This condition is more common in black populations, indicating a higher susceptibility.

We report a case of a 20-year-old Moroccan woman, who presented with pigmentation on the dorsum of her tongue, which had been present for 2 years. She did not have any accompanying symptoms. Her medical and family history was not relevant, and she was not taking any medication.

On physical examination of the oral mucosa, pigmentation limited to the fungiform papillae on the tip and lateral part of the tongue were seen (Fig. 1). No other physical abnormalities were found.

Liver tests, iron serum and kidney function were normal and no other family members were known with this anomaly.

The first report of pigmented fungiform papillae of the tongue (PFPT) was by Leonard in 1905.

Pigmented fungiform papillae of the tongue develop in the second or third decade of life, few cases are described in childhood [1].

Werchniak et al. suggested autosomal dominant inheritance, based on the presence of pigmented fungiform papillae in a mother and daughter.

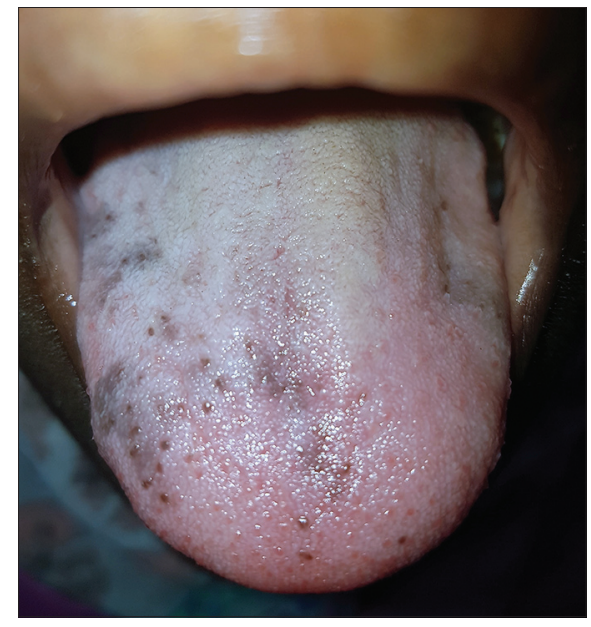

Figure 1: Pigmented fungiform papillae on the lateral border and dorsum of the tongue.

Different authors described an association with iron deficiency, haemochromatosis, anaemia or ichthyosis linearis circumflexa. In a clinical analysis of 58 Chinese cases of PFPT (2 males, 56 females), the authors hypothesise that certain pigmentary defects are possible triggered by abnormal secretion or fluctuation of sex hormones, with consequent the dropped-off melanin in the dermis [2].

The differential diagnosis of PFPT includes other causes of pigmentation of the oral mucosa, such as haemochromatosis, pernicious anaemia, amalgam tattoo, Peutz Jeghers syndrome, von Recklinghausen syndrome, Addison disease and black hairy tongue [3]. No effective treatment for PFPT has been described.

We describe the first case of PFTP in a moroccan woman. It's a rare benign entity which often leads to unnecessary investigations.

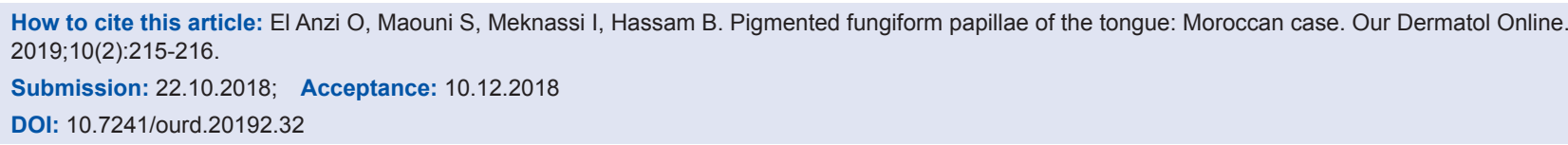


www.odermatol.com

\section{Consent}

The examination of the patient was conducted according to the Declaration of Helsinki principles.

\section{REFERENCES}

1. Karine Francine Docx M, Vandenberghe P, Govaert P. Pigmented fungiform papillae of the tongue (PFPT). Acta Clin Belg. 2016;71:117-8
2. Werchniak AE, Storm CA, Dinulos JG. Hyperpigmented patches on the tongue of a young girl. Pigmented fungiform papillae of the tongue. Arch Dermatol. 2004;140:1275-80.

3. Marcoval J, Notario J, Martín-Sala S, Figueras I. Pigmentation of the fungiform papillae of the tongue: a report of 2 cases. Actas Dermosifiliogr. 2011;102:739-40.

Copyright by Ouiam El Anzi, et al. This is an open-access article distributed under the terms of the Creative Commons Attribution License, which permits unrestricted use, distribution, and reproduction in any medium, provided the original author and source are credited.

Source of Support: Nil, Conflict of Interest: None declared. 